Original Article

\title{
Physical Activity Levels of the Physiotherapy Students in Rwanda during the Coronavirus Disease 2019 Lockdown Period
}

Sarah Uwamahoro ${ }^{1}$, Benjamin Ayabagabo ${ }^{1}$, Godfrey Nyamwasa ${ }^{1}$, Emmy Bucyana ${ }^{1}$, Gerard Urimubenshi ${ }^{1^{*}}$

${ }^{1}$ Department of Physiotherapy, College of Medicine and Health Sciences, University of Rwanda, KG 11 Ave, Kigali, Rwanda.

* Corresponding author: Gerard Urimubenshi. Department of Physiotherapy, College of Medicine and Health Sciences, University of Rwanda, KG 11 Ave, Kigali, Rwanda.Email: ugerardus@gmail.com.

\begin{abstract}
Background

The Coronavirus Disease 2019 (COVID-19) pandemic and related social distancing measures have an impact on physical activity levels.

Objective

To assess the physical activity (PA) levels of the physiotherapy students in Rwanda during the COVID-19 lockdown period.

\section{Methods}

We used a descriptive cross-sectional quantitative study design. Eighty-one participants were recruited, and data were collected using the International Physical Activity Questionnaire. We used descriptive statistics, Pearson Chi-Square and Kruskal-Wallis tests to assess whether there were statistically significant differences in physical activity levels according to demographic variables.

\section{Results}

The median total PA metabolic equivalent of task (MET)-minutes/week score for all the participants together was 3546 (IQR=8714), meaning high PA. The rates for high, moderate, and low PA levels were $54.4 \%, 31.7 \%$ and $13.9 \%$ respectively. Male and rural participants had higher median total PA MET score than females $(p=0.008)$ and urban residents $(p=0.018)$ respectively.

\section{Conclusions}

The PA levels of the study participants during the COVID-19 lockdown period were higher than the recommended standards. Females and urban participants appeared to be less physically active than their counterparts. Further similar studies and interventions towards PA promotion among university students in Rwanda during the pandemic are suggested.

Rwanda J Med Health Sci 2021;4(3):334-340
\end{abstract}

Keywords: COVID-19, Lockdown, Physical Activity, Physiotherapy Students, Rwanda

\section{Introduction}

Physical activity (PA) is defined as the total amount of time spent engaged in daily life activities, work and school activities, recreational and sports activities, and other activities that increase the body energy expenditure.[1] Having sufficient PA levels is also associated with a decrease in non-communicable diseases such as cardiovascular diseases, type-2 diabetes and other metabolic conditions,[2] as well as higher health-related quality of life.[3]
Furthermore, there is a positive significant relationship between $\mathrm{PA}$ and academic performance, and people who do regular PA have less chances of developing anxiety and depression as compared to those who do not practice physical exercise.[4]

The World Health Organisation (WHO) recommends that adults aged between 18 and 64 years should do at least 150 minutes of moderateintensity aerobic PA throughout the week or at least 75 minutes of vigorous-intensity aerobic PA throughout the week or an equivalent combination of moderate and vigorous-intensity activity.[5] 
This recommendation corresponds to a total PA score of at least 600 metabolic equivalent of task (MET)-minutes/week. For additional benefits, adults aged 18-64 years should increase their moderate PA to 300 minutes/week or their vigorous PA to 150 minutes/week,[5] which is equal to $1200 \mathrm{MET}-\mathrm{minutes} /$ week.

Despite the known benefits, the current Coronavirus Disease 2019 (COVID-19) pandemic was reported to have a negative impact on PA.[6] On 11th March 2020, the World Health Organization declared the COVID-19 as a pandemic.[7] The Government of Rwanda reported its first COVID-19 case on 14th March 2020. Then, like in many other countries, the Government of Rwanda took several extraordinary social distancing measures including lockdown to halt the spread of the pandemic. In addition to the closing of nonessential businesses, education institutions and places of worship, lockdown measures included the closing of sports facilities.

Several studies reported on lifestyle changes during home confinement. A recent systematic review revealed that the majority of 66 studies included in the review reported decreases in PA and increases in sedentary behaviours during their respective lockdowns across several populations.[8] An international study with data from Western Asia, North Africa, Europe, and other countries revealed that the COVID-19 home confinement has had a negative effect on all levels of PA and an increase in daily sitting time by more than 28\%.[9] Similar studies showed that there was a decrease in PA levels among the university students during the confinement periods, $[10,11]$ but the levels were still higher than the recommended 1200 METminutes/per week. For instance, an Indian study that involved physiotherapy professionals and students showed that the mean METminutes/week during the COVID-19 lockdown was $5,391 .[10]$

Individuals in low-income and middle-income countries like Rwanda are likely more affected by the stay-at-home rules than in high-income countries as they tend to have accommodations below the required standards and more confined spaces, making it difficult to engage in physical exercise.[3] In Rwanda, from March 2020 till January 2021, students were required to stay at home, online teaching and learning was initiated, and organized sports activities were suspended.
To the best of our knowledge, despite the global reports on a decrease in PA levels among students due to the COVID-19 pandemic and related measures, $[8,10,11]$ there is lack of information about the PA levels of the university students in Rwanda during the COVID-19 situation. Our purpose was to assess the PA levels of the physiotherapy students in Rwanda during the COVID-19 lockdown period. The study results would inform further studies and interventions aiming to promote PA in university students during the stay-at-home rules.

\section{Methods}

\section{Study design}

A descriptive cross-sectional quantitative study design was used.

\section{Subjects}

The study population consisted of all 87 registered physiotherapy students at the University of Rwanda (UR)-College of Medicine and Health Sciences (CMHS) for the academic year 2019-2020 (year $1, n=25$; year $2, n=19$; year $3, n=22$; year $4, n=21$ ). A census sampling strategy was used, but three students who assisted in data collection were excluded. Furthermore, three students did not have phones by which they could be contacted for data collection, and therefore, the study sample consisted of 81 participants.

\section{Materials}

The standardized short telephone administered International Physical Activity Questionnaire (IPAQ) was used to collect data. The IPAQ is a validated tool and has long (5 activity domains asked independently) and short (4 generic items) versions for use by either telephone or self-administered methods.[12] It was reported that the IPAQ has acceptable measurement properties for monitoring population levels of PA among 18 to 65 years old adults in diverse settings.[13] The purpose of the IPAQ versions is to provide tools that can be used to obtain internationally comparable data on healthrelated PA. The short form asks participants to recall, during the last seven days, the number of days per week and minutes per day spent engaging in vigorous $\mathrm{PA}$, moderate $\mathrm{PA}$, and walking. Similarly, the time spent sitting on a weekday was also recalled.

In addition to the IPAQ questionnaire, there were questions about the demographic characteristics including age, sex, residence area type (rural or urban) and academic year. 
Furthermore, the participants were asked to indicate whether there was a change in their PA during the COVID-19 related school closure as compared to usual holidays. Before data collection, the questionnaire was pilot tested on five non-physiotherapy students to explore its relevance and clarity to the Rwandan context. We found the questionnaire to be appropriate for our study purpose.

\section{Data collection procedure}

The data were collected via telephone calls in September 2020 and, during that period, schools, gyms and other sports and recreational activities were closed to control the spread of COVID-19 pandemic. The responses provided by the participants were recorded on individual questionnaires differentiated by the participants' codes.

\section{Data analysis}

Data were analysed using the Statistical Package for the Social Sciences (IBM Corp., USA) version 26. First, based on the guidelines for data processing and analysis of the IPAQ,[14] we determined the participants' PA levels through two stages.

Stage 1: Using the responses from the participants, we computed the metabolic equivalent of task (MET)-minutes/week for vigorous (V), moderate (M) and walking (W) activity using the following formula:[14] Walking MET $=3.3 \mathrm{x}$ walking minutes $\mathrm{x}$ walking days; Moderate MET $=4.0 \mathrm{x}$ moderateintensity activity minutes $\mathrm{x}$ moderate days; and Vigorous MET $=8.0 \mathrm{x}$ vigorous-intensity activity minutes $\mathrm{x}$ vigorous-intensity days.

Stage 2: Determining the combined total PA score using the following formula:[14] total PA $\mathrm{MET}=$ sum of Walking + Moderate + Vigorous MET minutes/week scores. The total PA MET scores are interpreted as follows:[14] High PA: total PA score of at least 3000 MET-minutes/ week; Moderate PA: total PA of at least 600 METminutes/week, but less than 3000 MET-minutes/week, and Low PA: those individuals who did not meet criteria for high or moderate PA were considered to have a 'low' PA level.

Second, we computed both descriptive and inferential statistics. These included the mean and standard deviation for age, median and interquartile range for the MET-minutes/week, as well as frequency and percentage for the categorical variables. We used the Pearson Chi-Square $\left(\mathrm{x}^{2}\right)$ test to assess whether there was a statistically significant relationship between the changes in PA during the COVID-19 related school closure and sex (male and female), residence urbanity (urban and rural residence) as well as academic year. Finally, we performed the KruskalWallis test to explore differences in the medians of the total PA MET-minutes/week scores as well as the time spent in sitting on a weekday according to sex, residence urbanity and academic year. The level of significance ( $\mathrm{p}$-value) was set at 0.05.

\section{Ethical approval}

Ethical clearance to conduct the study was granted by the CMHS Institutional Review Board (Ref. No. CMHS/IRB/291/2020). The eligible students were formally briefed about the study and the questionnaire, and were informed that the participation was voluntary, and they had a right to withdraw from the study at any time. In addition, the questionnaire was anonymous. All the students who were contacted consented to take part in the study.

\section{Results}

All 81 eligible physiotherapy students were reached with phone calls and responded to the telephoneadministered questionnaire, giving the response rate of $100 \%$. The mean age of the study participants was $22.5( \pm 2.162)$ years. Most of the participants $(62 \%)$ were living in rural regions. Only $30 \%$ of the participants were females. Table 1 shows the participants by academic year, sex, and residence urbanity.

Table 1. Distribution of the participants by academic year, sex, and residence urbanity

\begin{tabular}{lllllll}
\hline & n (\%) & Age, Years, & Sex, n (\%) & \multicolumn{2}{c}{ Residence urbanity, n (\%) } \\
& & Mean ( \pm SD) & Female & Male & Urban & Rural \\
\hline All & $81(100 \%)$ & $22.5( \pm 2.162)$ & $24(30 \%)$ & $57(70 \%)$ & $31(38 \%)$ & $50(62 \%)$ \\
Year 1 & $25(31 \%)$ & $20.9( \pm 2.128)$ & $9(11 \%)$ & $16(20 \%)$ & $6(7 \%)$ & $19(23 \%)$ \\
Year 2 & $18(22 \%)$ & $22.0( \pm 1.680)$ & $4(5 \%)$ & $14(17 \%)$ & $6(7 \%)$ & $12(15 \%)$ \\
Year 3 & $20(25 \%)$ & $22.9( \pm 1.137)$ & $7(9 \%)$ & $13(16 \%)$ & $9(11 \%)$ & $11(14 \%)$ \\
Year 4 & $18(22 \%)$ & $24.7( \pm 1.455)$ & $4(5 \%)$ & $14(17 \%)$ & $10(13 \%)$ & $8(10 \%)$ \\
\hline
\end{tabular}

Abbreviations: SD, standard deviation; $n$, frequency; \%, percentage 
More than half (54.3\%) of the participants reported a The analysis with stratification of the participants by decrease in physical activities during the COVID-19 sex, residence urbanity and academic level did not lockdown period as compared to usual holidays. show statistically significant differences $(\mathrm{p}>0.05)$ in PA changes (Table 2).

Table 2. Change in physical activity levels among the participants stratified by sex, residence urbanity and academic year

\begin{tabular}{|c|c|c|c|c|}
\hline $\begin{array}{l}\text { Participant character- } \\
\text { istics }\end{array}$ & $\begin{array}{c}\text { Increased } \\
\text { PA } \\
\text { n (\%) } \\
\end{array}$ & $\begin{array}{c}\text { No change in } \\
\text { PA } \\
n(\%) \\
\end{array}$ & $\begin{array}{c}\text { Decreased PA } \\
\text { n (\%) }\end{array}$ & P-Value \\
\hline All & $23(28.4 \%)$ & 14 (17.3\%) & $44(54.3 \%)$ & \\
\hline Sex & & & & 0.824 \\
\hline Female & $6(25.0)$ & $5(20.8)$ & $13(54.2)$ & \\
\hline Male & $17(29.8)$ & $9(15.8)$ & 31 (54.4) & \\
\hline Residence urbanity & & & & 0.250 \\
\hline Urban & 7 (22.6) & $8(25.8)$ & $16(51.6)$ & \\
\hline Rural & $16(32.0)$ & $6(12.0)$ & $28(56.0)$ & \\
\hline Academic year & & & & 0.068 \\
\hline Year 1 & $10(40.0)$ & $4(16.0)$ & $11(44.0)$ & \\
\hline Year 2 & 7 (38.9) & $5(27.8)$ & $6(33.3)$ & \\
\hline Year 3 & $5(25.0)$ & $3(15.0)$ & $12(60)$ & \\
\hline Year 4 & $1(32.0)$ & $2(32.0)$ & $15(32.0)$ & \\
\hline
\end{tabular}

Abbreviations: PA, physical activity; $n$, frequency; \%, percentage

As summarized in Table 3, the median total PA MET score for all the participants together was 3546, meaning high PA. However, $13.9 \%$ of the participants had low PA. The subgroup analysis indicated that the median total PA MET score for females, urban residents and second year participants varied between 1935 and 2691, corresponding to moderate PA. There was a statistically significant difference in median total PA MET score between males and females $(\mathrm{p}=0.008)$ as well as rural and urban residents $(\mathrm{p}=0.018)$.
The median time spent in sitting on a weekday in minutes was found to be 300 (IQR: 285) for females against 180 (IQR: 180) for males $(\mathrm{p}=0.062)$ and 300 (IQR: 360$)$ for urban against 180 (IQR: 180) for rural residents $(\mathrm{p}=0.024)$. The study results also revealed a statistically significant difference $(p=0.042)$ in PA levels between females and males with the latter being more physically active. 
Table 3. Physical activity levels of the participants according to sex, residence urbanity and academic year

\begin{tabular}{|c|c|c|c|c|c|c|c|c|}
\hline \multirow{2}{*}{$\begin{array}{l}\text { Participant } \\
\text { character- } \\
\text { istics }\end{array}$} & \multicolumn{2}{|c|}{ Total PA MET score ${ }^{a}$} & \multicolumn{2}{|c|}{$\begin{array}{l}\text { Time spent in } \\
\text { sitting }^{b}\end{array}$} & \multicolumn{4}{|c|}{ PA categories, $\mathbf{n}(\%)^{\mathrm{c}}$} \\
\hline & $\begin{array}{l}\text { Median } \\
\text { (IQR) }\end{array}$ & P-value & $\begin{array}{l}\text { Median } \\
\text { (IQR) }\end{array}$ & P-value & High PA & $\begin{array}{l}\text { Moderate } \\
\text { PA }\end{array}$ & Low PA & $\overline{\text { P-value }}$ \\
\hline All & $3546(8714)$ & & $240(240)$ & & $43(54.4)$ & $25(31.7)$ & 11 (13.9) & \\
\hline Sex & & 0.008 & & 0.062 & & & & 0.042 \\
\hline Female & 1935 (3847) & & $300(285)$ & & $8(34.8)$ & $9(39.1)$ & $6(26.1)$ & \\
\hline Male & $\begin{array}{l}4067 \\
(10232)\end{array}$ & & $180(180)$ & & $35(62.5)$ & $16(28.6)$ & $5(8.9)$ & \\
\hline $\begin{array}{l}\text { Residence } \\
\text { urbanity }\end{array}$ & & 0.018 & & 0.024 & & & & 0.122 \\
\hline Urban & $2691(4587)$ & & $300(360)$ & & $12(40.0)$ & $12(40.0)$ & $6(20.0)$ & \\
\hline Rural & $\begin{array}{l}4158 \\
(10916)\end{array}$ & & $180(180)$ & & $31(63.3)$ & $13(26.5)$ & $5(10.2)$ & \\
\hline $\begin{array}{l}\text { Academic } \\
\text { year }\end{array}$ & & 0.313 & & 0.412 & & & & 0.514 \\
\hline Year 1 & $\begin{array}{l}3813 \\
(10428)\end{array}$ & & $240(330)$ & & 16 (69.6) & $3(13.0)$ & $4(17.4)$ & \\
\hline Year 2 & $2244(7435)$ & & $300(240)$ & & 7 (38.9) & $8(44.4)$ & $3(16.7)$ & \\
\hline Year 3 & $\begin{array}{l}4730 \\
(10508)\end{array}$ & & $180(233)$ & & $11(55.0)$ & $8(40.0)$ & $1(5.0)$ & \\
\hline Year 4 & $3401(6001)$ & & $180(210)$ & & $9(50.0)$ & $6(33.3)$ & $3(16.7)$ & \\
\hline
\end{tabular}

Abbreviations: IQR, interquartile range; MET, metabolic equivalent of task; PA, physical activity; n, frequency; \%, percentage

a Interpretation for total PA MET scores: High PA: total PA MET minutes/week score of at least 3000; Moderate PA: total PA MET minutes/week score of at least 600, but less than 3000; Low PA: individuals who do not meet criteria for high or moderate PA.

b Time spent in sitting on a weekday in minutes

$\mathrm{C}$ As recommended in the guidelines for data processing and analysis of the IPAQ, two participants for whom data for numbers of days spent in PA were missing were removed from analysis.

\section{Discussion}

Although the majority (54\%) of the current study participants reported a decrease in PA during the COVID-19 lockdown period as compared to before the pandemic, the overall median PA core (3546 MET-minutes/week) was higher than the WHO recommendation of 1200 MET-minutes/week for adults aged between 18 and 64 years. The reported decrease in PA agreed with the findings from similar studies. $[10,11,15]$ A decrease in PA participation may result in commencement of or exacerbating existing diseases that have their roots in a sedentary lifestyle such as cardiovascular diseases, diabetes, obesity, colon cancer, high blood pressure, osteoporosis, lipid disorders, depression, and anxiety.[16] The distribution of the participants in low (13.9\%), moderate $(31.7 \%)$, and high (54.4\%) PA levels in an ascending order as found in our current study was also observed elsewhere.
For example, a study conducted in Switzerland showed that the proportions of participants classified as having low, moderate, and high PA were $4.6 \%, 32.5 \%$, and $62.9 \%$ respectively.[11]

Overall, despite the decrease in PA participation for the majority of the participants, the study results indicated that, during the COVID-19 lockdown period, the participants had a high PA. The possible explanation for this is that, although there was a closure of recreational and sports facilities, the participants were most likely much more engaged in domestic life activities, as some families may have been obliged to terminate the contracts with their domestic workers because of financial constraints caused by the pandemic. The finding of high PA during the COVID-19 lockdown period was consistent with the observations from studies conducted in India and Switzerland.[10,11] 
The median total PA score in our study $(3,546)$ was higher than the one $(3,447)$ found in the Swiss study.[11] This difference can be explained by the type of participants that were involved in the two studies. While our study was limited to physiotherapy students only, the Swiss one involved not only physiotherapy, but also nursing, nutrition and dietetics as well as midwifery students and employees. It was reported that physiotherapy students tend to be more physically active than the students from other disciplines.[11]

We found that females scored lower (median PA MET score $=1,935$, meaning moderate PA) than males (median PA MET score $=4,067$, meaning high PA) in terms of total PA MET score $(p=0.008)$. This was confirmed by the finding according to which females had higher median time spent sitting than males, although the difference was not statistically significant $(\mathrm{p}=0.062)$. A similar study in the United Kingdom also showed that female students had lower PA levels compared to males.[17] It has been reported that several factors hinder the participation of girls in PA. For instance, girls often have roles in their families which may limit the time available for them to engage in PA. Additionally, cultural expectations may restrict the participation of girls in certain forms of PA.[18]

We also found that students residing in rural regions scored higher total PA MET score than their colleagues in urban settings $(p=0.018)$. This finding was in agreement with the result according to which, on a weekday, participants in urban regions were spending more time sitting (median sitting time was 300 minutes) than the ones in rural regions (median sitting time was 180 minutes) and the difference was statistically significant $(p=0.024)$. This is likely true because in Rwanda like in other low-income countries, during their holidays, students from rural areas are often engaged in physically strenuous activities, for instance agriculture, house constructions, and diverse domestic activities. By contrast, those in cities spend more time seated, watching movies or games on television.

To the best of our knowledge, this was the first study that explored the PA levels of the physiotherapy students in Rwanda during the COVID-19lockdown period. We used a census sampling strategy, and we utilized a standardized questionnaire that has been used in many countries. We also followed the guidelines for processing and analysing the data collected using the IPAQ.[14]
However, our study was subject to some limitations. First, the participation in PA was not directly measured but instead it was selfreported by participants, and a reporting bias by drawing a too positive picture cannot be excluded. Second, although our study findings deserve attention, because of recall bias issues, we did not collect data about PA levels before COVID-19 for a better analysis of the impact of the pandemic on PA among the participants. Third, our study involved only physiotherapy students perhaps with better understanding of and engagement in PA, and the results cannot be generalized to students from all disciplines in Rwanda.

\section{Conclusion}

The PA levels of the study participants during the COVID-19 lockdown period were higher than the recommended standards. Females and urban participants appeared to be less physically active than their counterparts. This study provided the initial data that could be used as a basis for further studies and interventions towards PA promotion among university students in Rwanda during the pandemic conditions.

\section{Acknowledgments}

We are grateful to physiotherapy students at the University of Rwanda for devoting their time to participate in the study.

\section{Conflict of interest}

We declare that we have no conflict of interest.

\section{Authors' contributions}

SU, BA and GN designed the study, collected, analyzed, and interpreted the data, and wrote the first draft of the manuscript; EB and GU contributed to the design of the study, interpreted the data, and contributed to manuscript writing. All authors read and approved the final manuscript.

\section{Funding}

This research did not receive any specific grant from funding agencies in the public, commercial, or not-for-profit sectors.

This article is published open access under the Creative Commons Attribution-NonCommercial NoDerivatives (CC BYNC-ND4.0). People can copy and redistribute the article only for noncommercial purposes and as long as they give appropriate credit to the authors. They cannot distribute any modified material obtained by remixing, transforming or building upon this article. See https://creativecommons. org/licenses/by-nc-nd/4.0/ 


\section{References}

1. Howley ET. Type of activity: Resistance, aerobic and leisure versus occupational physical activity. Med. Sci. Sports Exerc. 2001;33:S364-9.

2. Calestine J, Bopp M, Bopp CM, Papalia Z. College Student Work Habits are Related to Physical Activity and Fitness. Int J Exerc Sci. 2017;10:1009-17.

3. Cavill N, Kahlmeier S, Racioppi F. Physical Activity and Health in Europe: Evidence for Action. Copenhagen: WHO Regional Office Europe; 2006.

4. Kayani S, Kiyani T, Wang J, Sanchez MLZ, Kayani S, Qurban H. Physical activity and academic performance: the mediating effect of self-esteem and depression. Sustainability. 2018;10:3633-49.

5. World Health Organization [WHO]. Global recommendations on physical activity for health. https://www.who. int/publications/i/item/9789241599979 (2010). Accessed 30 Nov 2021.

6. United Nations Department of Economic and Social Affairs Social Inclusion. The impact of COVID-19 on sport, physical activity and well-being and its effects on social development. https://www.un.org/ development/desa/dspd/2020/05/covid19-sport/ (2020). Accessed 31 Jul 2021.

7. World Health Organization. WHO DirectorGeneral's opening remarks at the media briefing on COVID-19 - 11 March 2020. https://www.who.int/director-general/ speeches/detail/who-director-general-sopening-remarks-at-the-media-briefingon-covid-19--11-march-2020 (2020). Accessed 30 Aug 2021.

8. Stockwell S, TrottM, Tully M, ShinJ, Barnett Y, Butler L, et al. Changes in physical activity and sedentary behaviours from before to during the COVID-19 pandemic lockdown: a systematic review. BMJ Open Sport Exerc Med. 2021;7:e000960.

9. Ammar A, Brach M, Trabelsi K, Chtourou $\mathrm{H}$, Boukhris O, Masmoudi L, et al. Effects of COVID-19 home confinement on eating behaviour and physical activity: Results of the ECLB-COVID19 international online survey. Nutrients. 2020;12:1583.
10. Srivastav AK, Sharma N, Samuel AJ. Impact of Coronavirus disease-19 (COVID-19) lockdown on physical activity and energy expenditure among physiotherapy professionals and students using web-based open E-survey sent through WhatsApp, Facebook and Instagram messengers. Clin. Epidemiol. Glob. Health. 2021;9:78-84.

11. Taeymans J, Luijckx E, Rogan S, Haas K, Baur H. Physical Activity, Nutritional Habits, and Sleeping Behavior in Students and Employees of a Swiss University During the COVID-19 Lockdown Period: Questionnaire Survey Study. JMIR Public Health Surveill. 2021;7:e26330.

12.The IPAQ Group. International Physical Activity Questionnaire. http://www.ipaq. ki.se (2002). Accessed 20 Aug 2020.

13. Craig CL, Marshall AL, Sjöström M, Bauman AE, Booth ML, Ainsworth BE, et al. International physical activity questionnaire: 12-country reliability and validity. Med Sci Sports Exerc. 2003;35:1381-95.

14. The IPAQ Group. Guidelines for data processing and analysis of the International Physical Activity Questionnaire (IPAQ) Short and Long Forms. http://www.ipaq. ki.se (2005). Accessed 16 Jul 2021.

15.Zenic N, Taiar R, Gilic B, Blazevic M, Maric $\mathrm{D}$, Pojskic $\mathrm{H}$, et al. Levels and Changes of Physical Activity in Adolescents during the COVID-19 Pandemic: Contextualizing Urban vs. Rural Living Environment. Appl. Sci. 2020;10:3997-4010.

16. Park JH, Moon JH, Kim HJ, Kong MH, Oh YH. Sedentary Lifestyle: Overview of Updated Evidence of Potential Health Risks. Korean $J$ Fam Med. 2020;41:365-73.

17.Aceijas C, Bello-Corassa R, WaldhauslN $\mathrm{S}$, Lambert $\mathrm{N}$, Cassar S. Barriers and determinants of physical activity among UK university students. Eur. J. Public Health. 2016. doi.org/10.1093/eurpub/ ckw174.255

18. World Health Organization. Physical Activity and Women. https://www.who.int/ dietphysicalactivity/factsheet_women/en/ (2021). Accessed 30 Aug 2021. 